\title{
CAMINHOS DA DESPOLUIÇÃO: AVALIAÇÃO DO RIO SÃO DOMINGOS NO PERÍODO DE 2000 A 2010
}

\section{Nome do Autor Principal:}

Cássia Aparecida Tambellini

\section{Nomes dos Co-autores:}

João Alberto da Silva Sé

Maria Teresa Vilela Nogueira Abdo

\section{Nome do Orientador:}

João Alberto da Silva Sé

\section{Instituição ou Empresa}

Centro Universitário de Araraquara - UNIARA

E-mail de contato:

cassiatambellini@uol.com.br,

Palavras-chave:

Gestão de recursos hídricos, bacia hidrográfica, despoluição

\section{INTRODUÇÃO}

A poluição dos rios resultante da ação antrópica desordenada e descomprometida com a sustentabilidade ambiental, tem sido amplamente veiculada na mídia como um dos principais problemas da atualidade e se agrava em grandes centros urbanos ou áreas de intensa exploração industrial e agrícola. A poluição dos recursos hídricos compromete de forma direta ou indireta a biodiversidade local, ocasionando a deterioração do solo, a extinção 
da flora e fauna, e compromete a qualidade de vida de todos que dependem deste recurso para sobrevivência. Esta situação alarmante requer uma visão interdisciplinar da questão na busca por soluções e certamente evolvendo órgãos públicos federais, estaduais e municipais, juntamente com usuários e a sociedade civil para melhor enfrentar a questão.

Por meio da Lei 7663/91, o Estado de São Paulo foi o pioneiro a estabelecer normas de orientação à Política Estadual de Recursos Hídricos, bem como criou o Sistema Integrado de Gerenciamento de Recursos Hídricos (SIGRH), que busca a execução, formulação e aplicação do Plano Estadual de Recursos Hídricos (PERH), congregando órgãos estaduais, municipais e a sociedade civil organizada. Com o apoio técnico do DAEE - Departamento de Águas e Energia Elétrica, o Estado de São Paulo foi dividido em 22 (vinte e duas) Unidades de Gestão dos Recursos Hídricos (UGRHIs), (SABBAG, 2010).

Neste contexto está inserida a região da Sub-bacia do Rio São Domingos, que se localiza no noroeste do Estado e é gerenciada pelo Comitê de Bacias com sede em São José do Rio Preto.

No Brasil, vários projetos visando à despoluição de rios têm sido estimulados por políticas públicas e iniciativas da sociedade, como por exemplo, o Programa de despoluição de bacias hidrográficas (PRODES), também conhecido como "Programa de compra de esgoto tratado", que consiste na concessão de estímulo financeiro pela União, na forma de pagamento pelo esgoto tratado, a prestadores de serviço de saneamento que investirem na implantação e operação de Estações de Tratamento de Esgotos (ETEs). O resultado das diversas ações que buscam a reversão desses problemas através de uma abordagem sustentável deve ser avaliado de forma concreta, pautada no diagnóstico inicial e avaliação final do processo e da área que recebeu os benefícios. Dentro da bacia dos rios Turvo e Grande muito são os projetos já instalados desde 2000, como mostram os relatórios dos Comitês de Bacias, mas, uma avaliação mais detalhada da sub-bacia do Rio São Domingos ainda não foi realizada. 


\section{OBJETIVOS}

\subsection{Objetivo Geral}

O objetivo deste trabalho é realizar um levantamento dos planos e projetos implantados nos municípios pertencentes à Bacia Hidrográfica do Rio São Domingos, sub-bacia do Turvo-Grande, relacionando-os com a possibilidade de redução da carga poluidora lançada no curso d'água durante o período de 2000 a 2010, pontuando e avaliando os possíveis ganhos ambientais frutos da conscientização e articulação da sociedade que possam ter influenciado na qualidade dos recursos hídricos no mesmo período.

\subsection{Objetivos Específicos}

- Realizar um levantamento dos programas e projetos implantados nos municípios pertencentes à Bacia Hidrográfica do Rio São Domingos e relacioná-los com a possibilidade de redução da carga poluidora lançada no curso d'água durante o período de 2000 a 2010,

- Identificar as ações e projetos de despoluição desenvolvidos por cada município pertencentes à Sub- Bacia do Rio São Domingos, por meio de questionários dirigidos aos municípios.

- Relacionar as ações, sucessos e insucessos obtidos de forma isolada ou integrada, e avaliar a articulação entre os agentes.

- Avaliar a participação do Comitê de Bacia nos projetos implantados neste período e o apoio financeiro junto à FEHIDRO

\section{METODOLOGIA}

\subsection{Diagnóstico da Bacia Hidrográfica do Rio São Domingos}

3.1.1 - Índice de Qualidade de Água

Serão utilizadas as análises estatísticas qualitativa e quantitativa, que ajudarão a provar ou não, que ações coordenadas de educação e prevenção, 
podem ajudar a reduzir a carga poluidora encontrada nos rios, neste caso, na sub- bacia do rio São Domingos. Primeiramente, objetivou-se avaliar o grau de poluição da bacia por meio dos índices de IQA (Índice de Qualidade da Água).

Nota-se que algumas características devem ser levadas em consideração nesta base de dados:

1 - são feitas coletas bimestrais em diversos pontos.

2 - no caso da bacia em análise, durante o ano de 2000 a 2004, os dados são referentes apenas ao ponto SDOM04500, ponto de coleta de água localizado no município de Catiguá, na Ponte da rua J. Zancaner.

\subsubsection{Aplicação de questionário nos municípios}

Para realizar um diagnóstico da situação do Rio São Domingos, foi utilizada a ferramenta estatística - análise qualitativa, sendo elaborado um questionário a todos os municípios integrantes da sub-bacia: Santa Adélia, Pindorama, Catanduva, Uchôa, Tabapuã, Cedral e Catiguá.

\section{RESULTADOS PRELIMINARES}

De acordo com os dados oficiais do Relatório da CETESB da UGHRI 15 de 2000 a 2009, foram tabulados os IQAs da situação ambiental da sub-bacia do Rio São Domingos e estes apresentaram resultados preocupantes sobre a qualidade da água desta bacia. Diante Da classificação da CETESB observase que nos anos de 2000 a 2004, no ponto de Catigua, só foram obtidos dados de qualidade de água de regular a péssimo. Já nos anos de 2005 a 2009, embora o índice de qualidade da água se apresente como regular a péssimo na sua maioria, em alguns momentos pode-se notar uma melhora na sua qualidade, chegando a registrar nível bom. Vários índices são utilizados pela Cetesb para a análise da qualidade das águas, como o IQA (Indice da Qualidade de Água), o IAP (Índice de Qualidade de Água para fins de Abastecimento Público), o IET (Índice de Estado Trófico), o IVA (Índice de 
qualidade de água para proteção da Vida Aquática) e outros. Para confirmar a qualidade da água da sub-bacia, foi utilizado o IQA, por se tratar de um índice mais abrangente.

Até o presente momento foram obtidas as respostas de três municípios a saber: Santa Adélia, Pindorama e Tabapuã. Deste modo com somente menos de $50 \%$ das respostas da população em análise, não há dados suficientes para chegar a uma resposta conclusiva. Nas entrevistas foi observado a conscientização de se investir na área de educação, como um meio de tentar prevenir o envio de carga poluidora aos rios e seus afluentes

Tabapuã e Pindorama apresentaram mais programas relacionados à melhoria dos recursos hídricos que Santa Adélia. Os municípios de Pindorama e Tabapuã apresentaram projetos financiados pelo FEHIDRO, enquanto que Santa Adélia não foi contemplada com tal recurso neste período.

Mudanças: Nos três municípios foram notadas mudanças: Santa Adélia apresentou projetos de recuperação de nascentes, de estradas e mata ciliar. Pindorama retirou o lançamento de esgoto in natura, melhorando a qualidade da água do rio São Domingos, ocasionando aparecimento de peixes nativos, como o lambari. Tabapuã declara mudanças, porém, ainda insuficientes para o objetivo visado.

Ações integradas: Santa Adélia relata envolvimento da comunidade e órgãos públicos em todos os programas. Tabapuã e Pindorama apresentam programas com participação absoluta do poder público.

Frutos: Santa Adélia considerou a reunião técnica eficaz por ter conseguido a participação de muitos envolvidos, agilizando a viabilização dos projetos. Pindorama considerou o Projeto Água Limpa mais eficaz, porque retirou do rio o principal fator de degradação. Tabapuã não relatou qual foi a mais efetiva.

No quesito informação sobre a poluição do rio e qualidade de água, foi feita a avaliação de 0 a 10. Tabapuã atribuiu nota 9(nove), Santa Adélia,7(sete) e Pindorama (zero). Nota-se que neste quesito, Tabapuã se apresenta mais bem informada. Quanto ao conhecimento da população em relação a 


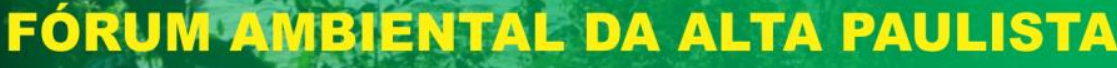 \\ V. 07, N: 02, 2011 - Categoria: Resumo Expandido

cobertura vegetal do seu município, Santa Adélia se apresenta mais bem informada, onde na avaliação de 0 a 10, obteve nota 4, enquanto que Tabapuã obteve 1 e Pindorama, 0 (zero). Quanto ao lixo, as três cidades apresentam elevado grau de conhecimento da situação, sendo que na mesma escala de 0 a 10, Santa Adélia obteve 9, Tabapuã 8,7 e Pindorama ,7.

\section{BIBLIOGRAFIA}

CBHTG - Comitê de Bacia Hidrográfica Turvo-Grande. Relatório Zero. São José do Rio Preto: CBHTJ, 1999.

CETESB, São Paulo . Relatório de qualidade das águas interiores do estado de São Paulo 2000 / CETESB. São Paulo . CETESB, 2001, pg. 2.

CETESB, Relatório de Qualidade das águas superficiais. São Paulo, 2009. p. $143,144$.

Constituição da República Federativa do Brasil de 1988. Art.26, Inciso I. Disponível em:

http://www.planalto.gov.br/ccivil 03/constituicao/constitui\%C3\%A7ao.htm. Acesso em 25/Nov/2010.

SIGRH - Sistema Integrado de Gerenciamento de Recursos Hídricos de São Paulo. Disponível em: www.sigrh.sp.gov.br/cgi-bin/sigrh.../cadastro. Acesso em 25/nov/10.

SABBAG, Edson Geraldo. Respeito à diversidade e autonomia dos Comitês. In: Revista Diálogo. São Paulo. 2010. p. 06. 